\title{
The Linguistic Status of Isotype
}

Christopher Burke, Reading

In a thorough study titled 'Neurath's theory of pictorial-statistical representation' (published over twenty years ago in Rediscovering the forgotten Vienna Circle) Karl Müller concluded that Otto Neurath never explicitly developed such a theory and questioned Neurath's claim that Isotype was a language, due to the weakness of evidence for this. In implicit agreement with Müller's analysis, this essay will draw on Neurath's correspondence and his 'visual autobiography' to show that he deliberately did not develop a theory of picture language, or even fully articulate a method, on the principle that it was too early in the history of visual education to make such definite statements. He also felt that such theorizing would restrict possible, future applications of Isotype.

There are some contradictions in the way Otto Neurath discussed Isotype, as perhaps there were in other areas of his work; Thomas Uebel has described him succinctly as 'a very contrapuntal writer'. ${ }^{1}$ It seems almost to have been a principle of Neurath's to be self-contradictory (or at least equivocal). In his 1942 essay 'International planning for freedom' he quoted Conrad Meyer: 'I am not a wittily constructed work of fiction; I am a human being and full of contradiction.' ${ }^{2}$ Neurath's habit of undermining certainty causes some difficulties of interpretation. He made statements claiming that Isotype was a kind of language, which should be in widespread use, yet he also admitted that it could never be a real language and he wanted to keep close control of how it was produced.

Neurath's book of 1936, International picture language, firmly established a claim of linguistic status for Isotype. The use of this phrase is partly 
explained by Neurath having written the book in C. K. Ogden's Basic English, which has a vocabulary of only 850 words to choose from. Nevertheless, Neurath stated in his introductory note that the rules he would explain in the book are 'in harmony with a complete system for an international picture language'. This is not something that he and his collaborators ever tried to develop, despite the claim for a system being made in the name Isotype itself - an acronym which stands for International System of Typographic Picture Education. In her account of how she invented this name, Marie Neurath confessed that it was not an 'entirely satisfactory solution'. ${ }^{3}$

The name Isotype replaced 'Vienna Method of Pictorial Statistics' (Wiener Methode der Bildstatistik) around the time that International picture language was being written, soon after Neurath and a group of close colleagues from the Gesellschafts- und Wirtschaftsmuseum in Wien had settled in the Netherlands. In correspondence at that time, Rudolf Carnap asked Neurath:

What does 'isotyp' [sic] mean? Representation by means of a similar picture? For a logician it rouses the association: 'of the same logical type'. Wouldn't it be possible to find another word? ${ }^{4}$

Carnap referred here to an interpretation based on the Greek words 'isos' (the same) and 'typos' (type, symbol). Neurath replied:

Isotype - the name for our picture language; we are glad we have it. Reidemeister [later Marie Neurath] developed it systematically: I-nternational S-ystem O-f Ty-pographic P-icture E-ducation. And it otherwise means: using the same types, which we in fact do. I hope it does not cause any great confusion among logicians. ${ }^{5}$

Neurath's last comment here - perhaps a little sarcastic in tone-indicates that he did not perceive Isotype as occupying the 'icy slopes of logic'; instead he welcomed the name as a kind of brand to effectively identify work produced at the International Foundation for Visual Education in the Hague. After leaving Vienna and losing the municipal subsidy given to the Gesellschafts- und Wirtschaftsmuseum, it was necessary to establish practice on a commercial basis. The Dutch Foundation struggled financially and, after two years in the Netherlands, Neurath wrote: 
But we can barely exist any longer, and don't know how things will go on, in spite of the positive attitude of important people towards our work, in spite of 'success' now again in educational circles. Just like our unified science has success - but it doesn't bring us one penny. ${ }^{6}$

Neurath may have been content to portray Isotype as a kind of 'system' and 'language' in order to enhance its appeal to potential clients during this difficult period.

Nevertheless, after the analytical debates about the use of language in the Vienna Circle, Neurath was naturally wary of using the term 'language' for referring to Isotype. He asked Carnap for advice on the matter during the writing of International picture language:

I am treating the work of our Institute theoretically and call it 'International picture language' [.] [I] indicate rules which we use and also show how one 'stresses' something - that corresponds to stylistic rules of [letter]spacing [in gothic type] and underlining, etc.

Now I would like to know how one should differentiate between the term 'script' and 'language'. In ethnology many speak of 'picture languages', others of 'picture script'. One speaks of Chinese script, although actually a language is meant whose translation into the spoken word is debatable.

I would prefer using a terminology which is consistent with yours. Please make some remarks. ${ }^{7}$

Neurath probably sought consistency with Carnap's book Logische Syntax der Sprache, which had been published not long before this request. ${ }^{8}$ Carnap replied:

I use the term 'language' in the broadest sense. I have hardly used 'script' or 'script language'. I would possibly use these terms in such a way that 'script' or 'script language' designate a special variety of language, namely the written variety. A system of rules for the use of pictures (to express facts) is then a special type of language. Hence it seems to me that one can use the term 'picture-script' as well as the term 'picture language'. ${ }^{9}$

Neurath took this as a kind of approval for calling Isotype a language: 'I will use the term picture language as you have indicated', he told Carnap. Yet he 


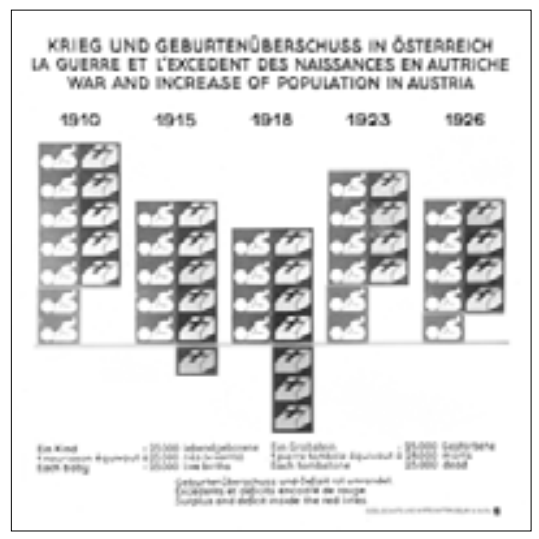

Fig. 1

\section{War and increase of population in Austria.}

Exhibition chart made at the Gesellschaftsund Wirtschaftsmuseum in Wien, c.1928 (T3d). A horizontal axis is used to draw attention to a surplus in births or deaths. Although this axis does not strictly correspond to ground level, this association is created by the birth symbols stacking above it, while death symbols descend below it.

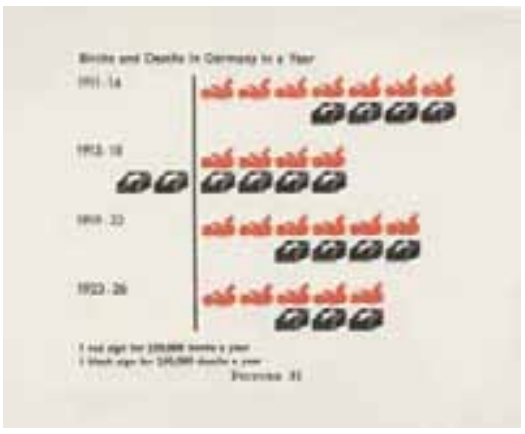

Fig. 2

Births and deaths in Germany in a year, from International picture language, 1936 (it is an English-language version of a chart published in Die bunte Welt, 1929). Here the axis has been given a vertical orientation, reflecting the adoption of a general rule to arrange pictograms in horizontal rows. Neurath made a naturalistic argument for this: 'The horizontal row corresponds to the customary position of the objects. People, animals, and cars move horizontally over the earth's surface. It would be strange to arrange people one on top of the other.' ${ }^{10}$

was hesitant about taking this step, explaining that he had previously used only the term 'picture script' [Bilderschrift]. Indeed, in his longest and most detailed account of the Vienna Method-Bildstatistik nach Wiener Methode in der Schule (1933) - he seems quite deliberately to have used this term and avoided 'picture language' [Bildersprache]. To Carnap, he continued:

... it is naturally something else if there is a picture language with its own syntax, or a picture language without its own syntax. Translatable word for 
word, so to speak. The German script-language itself is different from the German speech-language. Above all in 'style', which is also language. ${ }^{11}$

Neurath pointed out in International picture language that Isotype could not translate verbal language 'word for word'; but it did have some basic syntactical rules, which were established during the Vienna period. The basic rule is that pictogram units should not be increased in size to indicate an increase in quantity, but should instead be repeated in greater numbers, at the same size. After initial years of experiment, it was also resolved to line them up in horizontal (not vertical) rows, with time running on the vertical axis. Arranged this way, Neurath likened the pictograms to letters composed in a printed line. ${ }^{12}$

Some examples were prepared around 1936 to show how statements such as 'boy walking through doorway' should be conveyed through Isotype, with counter-examples (figs $3 \& 4$ ). These make clear that Isotype has no components that are directly equivalent to words in many cases; but it would be difficult to interpret rules which dictate that these statements should be conveyed in precisely the approved configurations given here. Perhaps this

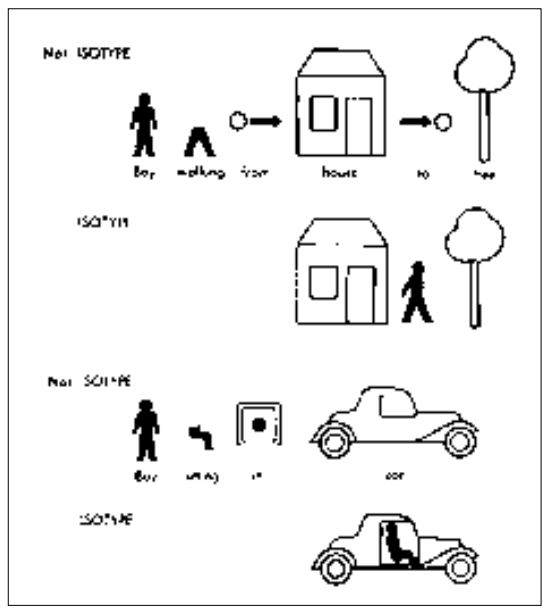

Fig. 3 \& Fig. 4

Examples of 'not Isotype' and Isotype depictions of some simple operations.

c. 1936 (T1413 \& 1414)

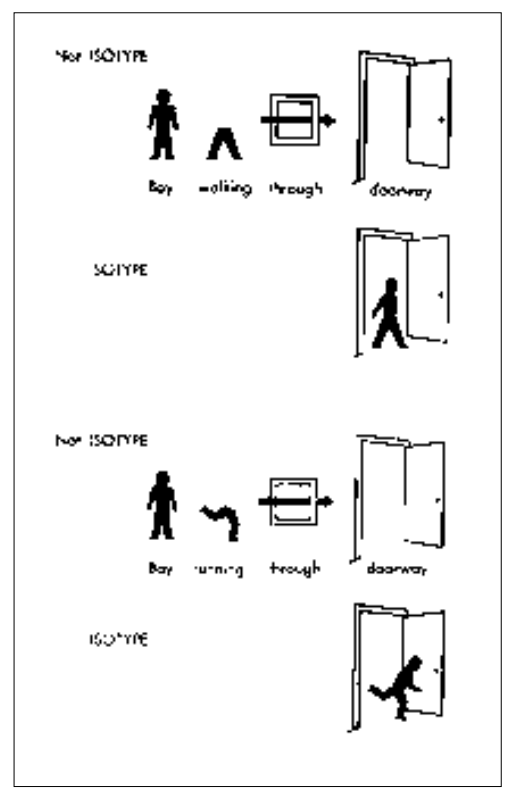




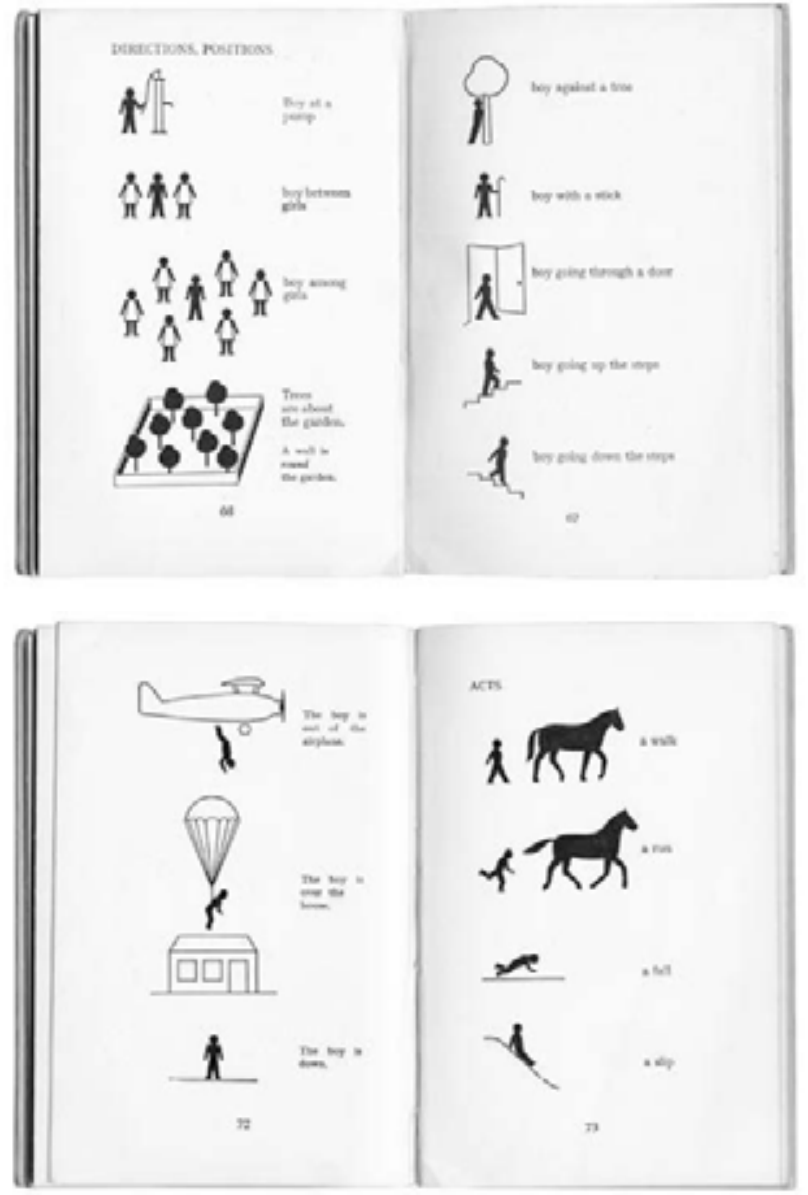

Fig. 5 \& Fig. 6

Pages from

Basic by Isotype

(London:

Kegan Paul, Trench,

Trubner \& Co., 1937)

was the point - that there should always be flexibility to allow for economical (and creative) graphic renditions. (More examples of this kind appeared in Basic by Isotype, the book that was prepared alongside International picture language.)

Almost a decade after writing International picture language, Neurath continued to refer loosely to Isotype as a 'visual language' in a book titled 'Visual education', which he wrote towards the end of his life. He seemed to recognize the debatability of his usage, however: 
If one shows realistic pictures instead of using impressive sentences or expressions, one uses a language which is a rather vague one, but vagueness in itself is no objection as long as ambiguity is avoided. ${ }^{13}$

Contemporary with this, in his 'visual autobiography' titled From hieroglyphics to Isotype, Neurath clarified that Isotype was not a language but a 'languagelike technique':

There are many reasons why Isotype cannot be developed as a 'complete language' without destroying its force and simplicity. Our daily language, even in primitive societies, is to some extent richer than our Isotype representations can be, and one needs words added to the pictures. ${ }^{14}$

Around the same time he wrote to a colleague in England:

I object to all attempts to look at Isotype as a a quasi-language in full dress. It is just my point to maintain, that Isotype is adapted to impressive presentation of relatively simple correlations. A full scheme of Hieroglyphics should frighten me. ${ }^{15}$

Neurath had admitted this in other words already in International picture language, calling Isotype a 'helping language' (in later writings he called it an 'auxiliary language').

While International picture language remains the best written account of Isotype, it should not be interpreted as a set of definitive statements that wholly encapsulate what was an activity of collaborative, graphic design. Taking that book as a summa ignores the rich and varied history of Isotype between 1924 and 1971, and encourages an appraisal of Isotype in purely conceptual terms. Neurath's epistemological (and economic) writings enrich an analysis of Isotype, without doubt; but he certainly never considered it as a philosophical exercise. He often commented to colleagues and clients that Isotype could not be fully explained but only demonstrated in action.

The makers of Isotype clearly did not want to construct a whole language; Isotype was instead an approach to design for education, with some linguistic aspirations. Its few basic rules provided a certain systematic aspect. Neurath hesitantly referred to 'Isotype vocabulary and the Isotype grammar, if one is allowed to use these terms in such a context'. ${ }^{16}$ Some rough parallels with 
language can be drawn: for instance, in the way that pictograms could be combined to create the equivalent of compound nouns. Also, by linguistic analogy, a certain significance was attached to changes in form or colour; they were not changed arbitrarily.

To some extent Isotype was defined by what it did not do - what was left out. There is a similarity here to the way in which Neurath simply left out specific words from his vocabulary when writing, in order to avoid certain complications. Isotype generally never shows things in perspective, for example, because Neurath thought that such naturalism detracted from the power of the simplified imagery.

In From hieroglyphics to Isotype Neurath stated that the Isotype team attempted to achieve a 'visual consistency' lacking in some previous efforts in visual communication. Yet, on the same page (103), he claimed that 'I think we were the first to evolve a theoretical framework of visualization'. This sounds suspiciously like the very thing which he criticized other people for doing, although it is perhaps a reasonable description of the broad rules formulated for Isotype. Such a phrase, added to claims for Isotype to be an 'international system' and a 'picture language', may encourage interpretation of it as having a utopian aspect. Karl Müller observed that Neurath thought 'full symbolic languages' were something desirable but not practicable. ${ }^{17}$ There is no way of breaking down Isotype into definite components of meaning any more than verbal language could be, in Neurath's view:

I cannot deny that many scientifically minded people do not like such a start full of vagueness; they would prefer - as I would prefer too, if I did not regard this wish as a utopian one - to start with exact initial definitions and atomic simple elements. ${ }^{18}$

Isotype was not any kind of 'ideal language', which is what Neurath described Carnap as having attempted to develop in his book Der logische Aufbau der Welt (1928). ${ }^{19}$ Neurath considered Carnap's formulations as inapplicable to the social sciences (the principal province of Isotype) because they did not reflect the necessary mixture of 'clean' and 'unclean' ways of thinking. In his autobiography Carnap recalled that Neurath insisted on the materiality of language: 
Neurath emphasized from the beginning that language phenomena are events within the world, not something that refers to the world from outside. Spoken language consists of sound waves; written language consists of marks of ink on paper. Neurath emphasized these facts in order to reject the view that there is something 'higher', something mysterious, 'spiritual', in language, a view which was prominent in German philosophy. I agreed with him but pointed out that only the structural pattern, not the physical properties of the ink marks, were relevant for the function of language. Thus it is possible to construct a theory about language, namely the geometry of the written pattern. ${ }^{20}$

Here is a significant difference between the views of Carnap and Neurath: Carnap's response, to dismiss the physical properties of graphic language as irrelevant, showed his vestigial attachment to the idealism of German philosophical tradition; Neurath had been occupied since the early 1920s with designing and producing graphic material and, for him, the particular form of ink marks on paper were not incidental - they were intrinsic to Isotype.

This difference between Carnap and Neurath emerged during the seminal 'protocol sentence' debate within the Vienna Circle. Neurath argued that 'What is first given us is our historical ordinary language with a multitude of imprecise unanalysed terms ["Ballungen"].' ${ }^{21}$ In his view protocol statements were not intended as 'elementary statements' - 'In this form they are even a protest against elementary statements.' ${ }^{22}$ As an example he gave the sentence 'Otto observes an angry man': this was imprecise because 'angry man' is not precisely defined ('but "Otto" itself is in many respects an imprecise term', he added). 'We start by purifying this ordinary language of metaphysical components and thus arrive at the physicalist ordinary language. A list of forbidden words can serve us well in doing this.' ${ }^{23}$ Such a 'physicalist language' is also served by using pictures instead of words: pictures make a direct, iconic connection to the physical world, not a symbolic one. Yet the Isotype pictograms representing 'man' or 'woman' are by nature imprecise - they are deliberately generic. In Neurath's terms, they are also 'Ballungen', imprecise clusters of concepts. ${ }^{24}$ The graphic simplification in Isotype is instrumental, and does not correspond to a reduction of connotation. Isotype pictograms are generalized pictures due to their simplicity. Neurath commented: 'The figures must not function as individuals, rather as symbols for a genus [Gattung].' ${ }^{25}$

Although Neurath recognized no direct descent of Isotype from either hieroglyphics or Chinese script, he found some analogies with these 

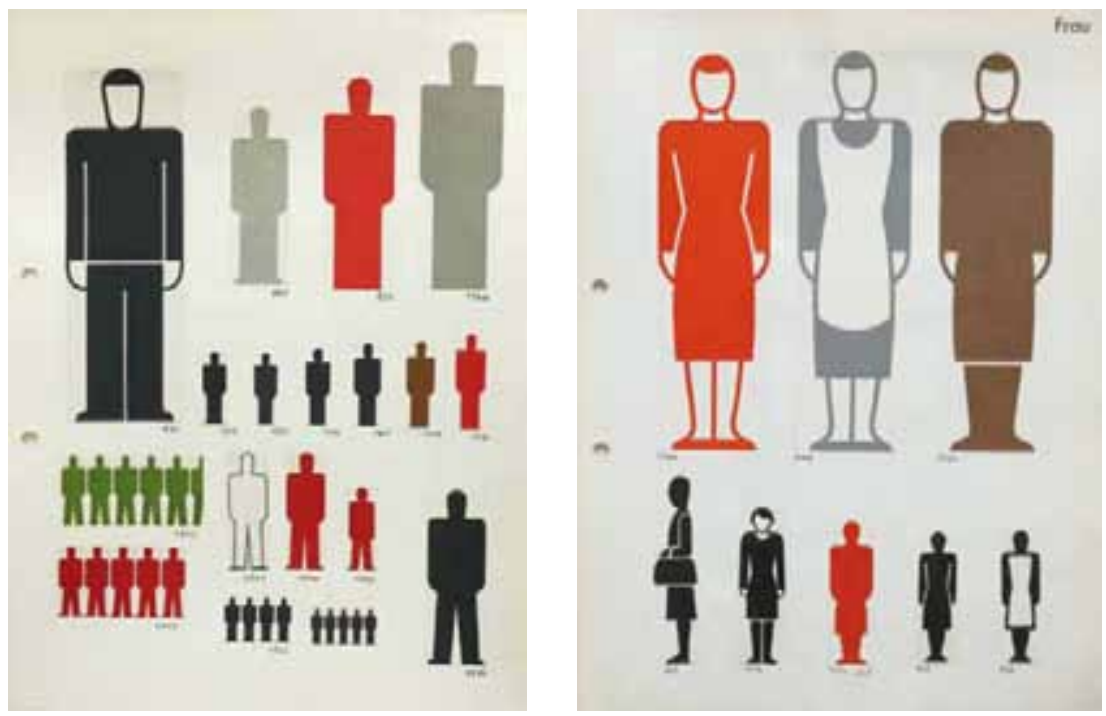

Fig. 7 \& Fig. 8

Pages from the Isotype 'picture dictionary', with pictograms designed by Gerd Arntz in collaboration with Otto Neurath. 1930-4. The solid silhouette version of 'man' with legs together (top right of left sheet) was sometimes used to depict 'person' (both sexes).

historical 'picture scripts'. ${ }^{26}$ He compared their advantages with those of alphabetic script:

A people with a conceptual script (like the Chinese, for instance) has difficulties in creating a freely mobile symbolism; on the other hand, it runs less easily into the danger of talking philosophical nonsense. ...

... letters as signs without conceptual meaning are, however, well suited for a strictly scientific symbolism. ${ }^{27}$

Care must be taken in mapping Neurath's views about verbal language onto his work in picture language. There are some enticing similarities, but the shift from word to image is, in Isotype terms, a 'transformation' or metamorphosis [Umwandlung] of linguistic mode, which entails more differences than similarities. However, to make a crude analogy, Isotype charts could 
be seen as a kind of graphic protocol statement lacking the rigour of the verbal kind defined by the bracketed qualifications about who exactly made the observation and when. Although Isotype charts bear the signature of the Isotype Institute (and before that the Gesellschafts- und Wirtschaftsmuseum or the Mundanæum), the origin and editing of the information contained in them is rarely made explicit: sources of statistics are often only given when a book appendix allows space, for example.

Neurath was not interested in analytical systems that pretend to classify whole languages. As Herbert Feigl noted, Neurath was 'skeptical if not outright opposed to' semantics as developed by Carnap. ${ }^{28}$ In 'Foundations of the social sciences' he stated:

I think that 'semantics', as evolved by Carnap and [Alfred] Tarski, will support many kinds of calculus analysis, but I feel uneasy when thinking of its application to empiricist arguments and the danger of slipping into 'ontological' ways of arguing. ${ }^{29}$

For the same reason Neurath had reservations about the theory of 'semiotic' (singular, not plural) expounded by the American philosopher Charles Morris in a long essay titled 'Foundations of the theory of signs' for the first volume of the International Encyclopedia of Unified Science. Neurath was editor-in-chief of this encyclopedia, although he seems to have left the editing of Morris's essay mainly to Carnap, who was assistant editor (along with Morris himself). Neurath gave Morris's essay the title 'Semiotic' in an initial contents list, having noted Morris's previous use of the word, but Morris resisted it as a title 'because the term is not known to many people', and instead proposed 'Theory of signs'. Neurath welcomed this as 'a real name of a science'. Yet he considered Morris to have gone too far in terms of constructing a system of classification: he agreed with Morris that one should try to 'systematize' as far as possible, without pretending to make a complete or final system - this was essentially the approach in Isotype - but it seemed to him that in Morris's study 'the classification exceeds the clarity that can be attained in this area at the present time'. 'I fear that too much terminology in an area that is so little developed does not have a clarifying effect. ${ }^{30}$

It is perhaps significant that Neurath barely mentioned Morris or Semiotic[s] in his introduction to volume one of the Encyclopedia; he mentioned more favourably the linguistic discipline of Significs, which 


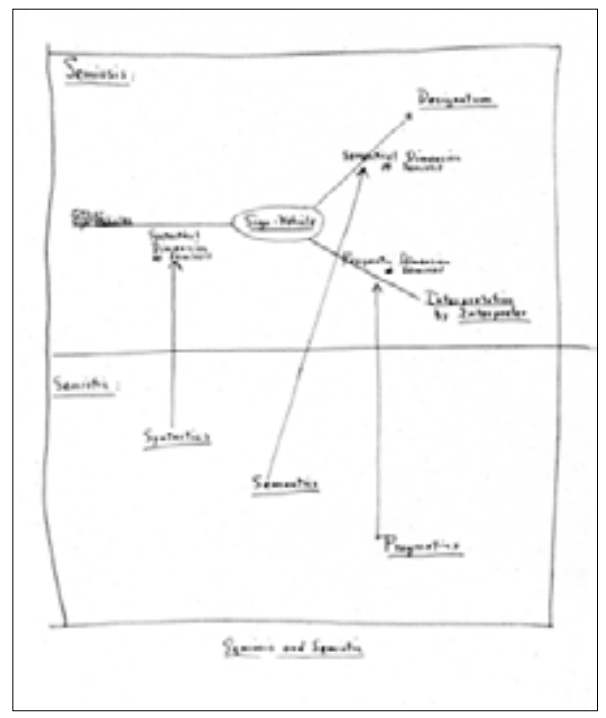

Fig. 9

\section{A diagram by Charles Morris} titled 'Semiosis and semiotic'. This was included in a letter he sent to Neurath, 3 February 1938. (VCA-m)

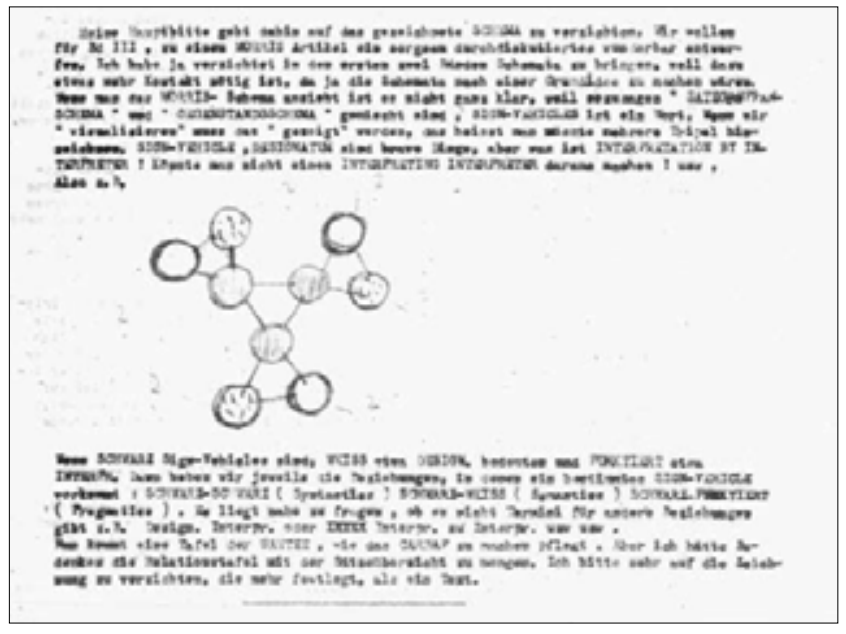

Fig. 10

Extract from Neurath's reply to Morris, 14 February 1938, including his diagram based on Morris's concepts. Neurath's version tends toward Isotype in being purely visual, with separate verbal explanations. It also begins to resemble an atomic diagram. In the text below he appears to introduce the term 'design', but this is an abbreviation of 'designatum', as used by Morris. (VCA-m) 
responded principally to the pragmatic aspect of language ${ }^{31}$ In his introduction Neurath offered an epigram that illuminates study of much of his work: 'One can love exactness and nevertheless consciously tolerate a certain amount of vagueness.' He continued: 'How can one combine such a critical and skeptical attitude with the unparalyzed driving power which is needed to attain success in social and private life?'32

Neurath was consistent in observing that visualization had strong limitsthat it was capable of less complexity than verbal language. He discussed this matter with Patrick Meredith, a member of the advisory committee for the Isotype Institute in the UK. Meredith established a Visual Education Centre at University College, Exeter (in south-west England); he also became the first lecturer in visual education in Britain. He met several times with Neurath, and some of Neurath's ideas are clearly recognizable in short essays written by Meredith in the early 1940s. He described the work of his 'Visual Education Centre' as 'concerned with the bearing of three normative disciplines on visual production, namely logic, semantics and statistical theory'. ${ }^{33}$ Neurath was doubtful about establishing visual education as some kind of academic discipline by pretending that it was more developed than it really was:

I think the Visual Education business is in the beginning. It seems to be rather dangerous to create terms for such a provisional activity. The statements one wants to make are poor and few only. After some research work you will perhaps need a few terms.

My answer is: try to discover how visual education goes on at the moment, particularly in certain disciplines. Even a first rather vague information would mean a lot, since one does not know anything about the state of affairs. From such research you will reach certain results and making descriptive statements, perhaps, maybe, you will use some expressions frequently, which afterwards will be fixed by use and then become elements of the normal discussion, but I think it hardly desirable to start with such phraseological attempts before any clear results have been reached. You see from my articles how careful I avoid to use particular terms. [sic] I try to remain within the daily life language realm. I avoid even acknowledged expressions of modern psychology, knowing how many misunderstandings may grow up from that. Therefore I suggest to speak simply and frankly of the problem without anticipating any classification or hypothesis. ${ }^{34}$ 
Neurath's resistance to Meredith's use of the phrase 'visual logic' led him to admit that 'logic' had been on his notorious list of 'dangerous' words since the Unity of Science congress of 1937, which, he conceded, put him in a difficult position: 'In short, I myself do not know how to apply the term properly, and therefore - against my intentions, because we speak of Logical Empiricism - I dropped the term altogether. ${ }^{35}$ By contrast he seemed content to use the word 'language' in a rather loose way, possibly expanding its definition, without fear of creating confusion.

Meredith claimed that 'visual language' is 'a richer and more powerful medium of expression than verbal language'-Neurath disagreed:

... you want to present our Isotype or Visual Education in general as something 'theoretically' better evolved than something else in the field of verbal presentation. I cannot see that. But I think you have the desire to give the Visual Education business some 'higher' marks than it deserves. You see such overstatements may induce people to reply and then we shall be in a bad position, because we cannot show how fine Visual Education is in supporting theoretical analysis - it is not. ${ }^{36}$

Neurath also objected to Meredith misrepresenting one of Neurath's ideas by stating that 'visual expression' is 'multi-dimensional': ${ }^{37}$

you write, that Visual Education by means of its more dimensions is better adapted to the more dimensions of modern thinking. I said just the opposite. The visualization is based on three or two dimensions, that is sometimes an advantage from the viewpoint of impressiveness, compared with the writing appearance of one dimension.

But, scientific reasoning needs an indefinite number of dimensions, this is just given by our writing, but not by visualization. The presentation is more impressive but is relatively poor, poorer than our language, and that is, I think one fair reason, why some people subconsciously and consciously are against visualization, I myself have this serious criticism. ${ }^{38}$

After Otto Neurath's death Marie Neurath continued to warn Meredith about being too theoretical (he appears to have been constructing an analytical framework called 'semagraphics'): 
I will tell you why I cannot see how your approach could help me any further. I cannot see how you can show, by making your structure in the epistemic space, whether a lesson or a chart or a chapter is good or bad educationally. It is the same with your semagraphics as far as I understand it. It seems to me that you can find a place for any type of representation, whether good or bad or senseless. Why then the whole trouble? Don't you want to find out what is good and what bad in visual education? Why not help to develop methods to find this out?

This was what Otto tried to impress on you during the last long talk wasn't it? ? $^{39}$

The Neuraths' priority was creating graphic material, not primarily analysing it. Their concern was a practical one - to design visual material that conveyed information clearly, and they were interested in research if it helped to show what was effective in practice. Indeed Neurath had approached the influential professor of psychology at the university of Vienna, Karl Bühler, about making some scientific studies with Isotype material. ${ }^{40} \mathrm{He}$ was open to research on the assumptions behind Isotype, commenting to Meredith: 'I would like to make experiments and research dealing with problems of "icons" and verbal expression. The borderline between word language and picture language is insufficiently analyzed.'

\section{International system or proprietary technique?}

In From hieroglyphics to Isotype Neurath reflected:

The history of hieroglyphics covers a long period, while the history of Isotype as yet covers barely two decades. During this short time it has become somewhat stabilized and is now only changing like a language, which also alters and enriches its vocabulary, grammar and style. (104)

But, unlike most languages, it was intended for one-way communication. It was not a language offered for anyone to create statements for themselves. In terms of reading, Isotype should require little or no learning; Neurath hoped that looking at Isotype was not much different than looking at the real world. But creating statements with Isotype was complex and, in his view, 
required a certain attitude - essentially that of Logical Empiricism. 'Isotype is not just the application of symbols [pictograms] to something,' he remarked to a colleague, 'it implies a particular attitude, which needs careful treatment before becoming successful. ${ }^{42}$ He explained to Patrick Meredith that 'Isotype education is similar to empiricist education and is connected with a certain alteration of attitude, teacher and pupils. ${ }^{, 43}$

Neurath gave more details about this 'attitude' to R.W. Moore (headmaster of a well-known private school in England named Harrow):

You see our educational tendency is to present problems in a simple way, not by transforming verbal generalizations again, but, as far as possible by presenting descriptive items, from which the reader may infer a generalization. Of course even that has not to be handled in a rigid way.

We try to start from something you can understand as a plain man, without particular education. We think that one may present something of any problem, one can discuss properly, in this way - but not the whole problem. A selection is unavoidable because visual representation is something coarse and primitive. ${ }^{44}$

He summarized this approach to another colleague: 'The point is: in Isotype we avoid "analogies", we try to present either concrete factual items or symbolic relations." ${ }^{45}$

The application of Isotype to consistent design and production of graphic information is accurately reflected by Neurath's description of it as a 'language-like technique'. It could be argued that it was a proprietary technique, due to the fact that it was never fully systematized, or even fully articulated. Neurath suggested that there was a secret ingredient in Isotype already during the Vienna period:

For it is clear that the 'Vienna Method' is, unlike the usual graphic methods, not a machine into which one throws sequences of figures in order to get quantitative pictures. The 'Vienna Method' requires creative [gestaltende], educational work. ${ }^{46}$

Marie Neurath described the work of design in Isotype ('transformation') as requiring 'educational tact' [pädagogischen Takt $].{ }^{47}$

During the last years of his life Otto Neurath recognized that the Isotype method remained somewhat elusive: 
Up to now there is no Isotype curriculum in existence which would enable people to learn this new technique properly from the start. It is more or less routine work, based on a great many rules, the application of which depends upon a highly skilled judgement. ${ }^{48}$

But he did not accept others freely adapting Isotype principles. There was a right way to do it, in his view, which was partly covert: he insisted that any prospective Isotype 'transformers' should be trained only at the Isotype Institute. Neurath explained this to his son, Paul, who began to teach the visualization of statistics in the USA during the early 1940s:

We devoted many years to Visual Education. Sometimes we thought, perhaps one could make the subject teachable in a simple way, but after experience and research we discovered that only a team of highly skilled people are able to make transformations and to create charts and models composed of standardized elements. Long training is needed, years.

He reiterated the point that he had made about the Vienna Method:

We discovered that one cannot make automatically Isotype charts, as one cannot make automatically musical compositions, or architecture or something else, in spite of the fact, that there are rules which regulate the conventions. ${ }^{49}$

When discussing the same issues with Meredith, Neurath added that the matter 'touches many principles of the transfer of abilities and skill'. ${ }^{50} \mathrm{He}$ saw Isotype chart-making as a craft that could only be learned by apprenticeship.

Otto and Paul Neurath had a strong disagreement with each other about the propriety of Isotype - and their discussion of the matter is informative with regard to Isotype not being an easily teachable system. Otto Neurath criticized his son for pretending to teach a subject without sufficient experience of it; his disapproval was partly linked with his dislike of the adaptation made of Isotype in America by Neurath's former colleague Rudolf Modley. Paul Neurath showed a page from Modley's book How to use pictorial statistics (1937) to his students because Otto Neurath himself had not written a book on 'how to make' Isotype charts (International picture language is too full of equivocation to be such a book). His father explained to him the differences between conventional, schematic visualization and Isotype: 


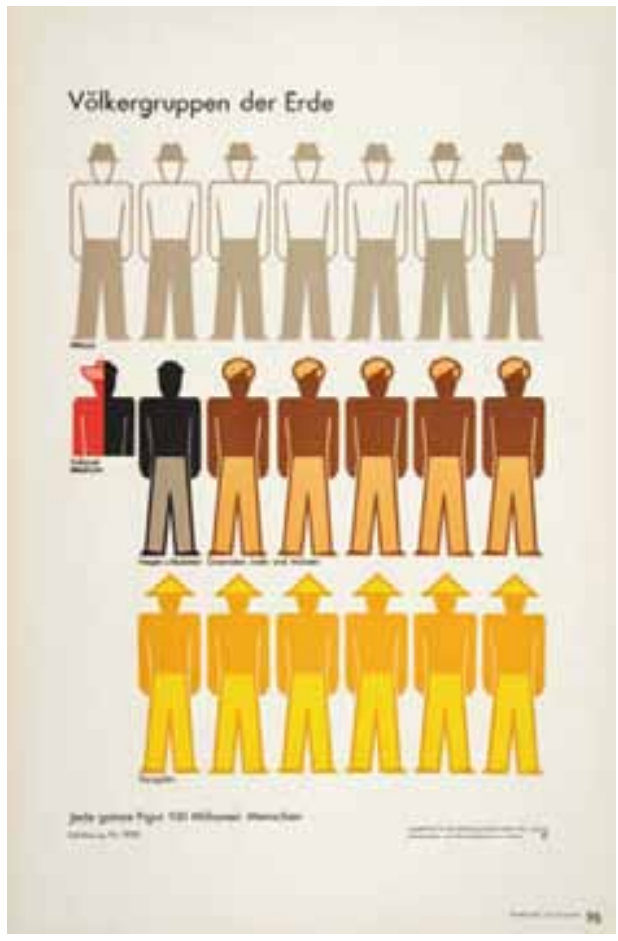

Fig. 11

\section{Chart 'Völkergruppen der Erde' (human groups of the earth) from Gesellschaft und Wirtschaft (1930).}

Estimated data for 1930; each whole figure represents 100 million people. This particular graphic solution for showing relative population is not as obvious as it may seem. An alternative design could have featured generic pictograms for '[hu]man' placed in rows on the particular areas of a world map to which they belong. Instead, a striking correlation emerges if humanity is grouped in three categories'white', 'brown/black' and 'yellow' people (as Neurath called them). So the pictograms were designed (and coloured) to convey directly these racial distinctions, and simply lined up in three rows to emphasize the similarity in quantity between the groups. Neurath commented that most people believed wrongly that there were roughly three or four times as many 'yellow' people as 'white' in the world; but looking at this chart, he asserted, made it difficult to forget that there were roughly the same amount of each at that time. ${ }^{51}$

Visualization by means of geometrical devices is a work, which skilled people can learn, but visualization by means of Isotype is something wholly different, because here the educational decision enters the field. To present something impressively, implies dropping something, making rough figures instead of exact figures, but not in a systematized way, but from case to case. A technique of presentation very useful today may be not useful tomorrow ... the mankind chart [fig. 11] very good as long as you get the three rows-fine. If alterations appear, perhaps the arrangement should be changed ... And 
that is something startling for many people. The substitution of bars by rows of puppets becomes boring and if you want to be exact you are destroying the effect of Isotype. To explain these finesses needs an intense analysis - even if one devotes only three hours to the presentation of the results. ${ }^{52}$

A balance of unity with variety was essential to Isotype, in Otto Neurath's opinion, as he explained to Meredith:

we always fear that the vivid and imaginative element of Isotype could be too much pedantically framed and transformed into a kind of litany ... The combination of a unified language with a multiplicity of striking expressions, that is the secret of the Isotype habit. ${ }^{53}$

Variety was important in making each chart as individual as possible within the limits of Isotype because memorability was central to its educational aims. During the period of the Vienna Circle's linguistic debates, Neurath wrote with polemical overstatement: 'In language nothing but order is essential, and that is already represented by a sequence of signs in Morse code. ${ }^{54}$ It is clear, however, that while he may have considered order the only essential aspect of language, he did not consider it the only desirable feature. This applied to 'picture language' too:

Isotype 'writing' is like writing a novel in any language. It is not sufficient - as everybody realizes - to know the words and the grammar; one also has to know how to select combinations of words to produce a striking result. ${ }^{55}$

He developed this point in correspondence with a colleague:

I myself stress the point, that Isotype is mainly a technique of educational style and a highly complicated grammar. The elements are stable, but the wit is in the arrangement, like Shakespeare is in the arrangement not in the dictionary of our English language. Isotype is the name of this technique executed by a team of highly skilled people. ... I should not speak of 'perfection'. The Isotype stock will be enriched, never finished ...

Here Neurath added two further important observations: that Isotype should be open ended - an accumulative, encyclopedic enterprise; and that it 
was a collaborative process of design and craft, not a fully theorizable system. All the skills involved - from analysing data to sketching graphic configurations, to cutting out pictograms and sticking them down as part of the final artwork - were important and had their place.

But the fulcrum of Isotype work was 'transformation', and it was this creative design work which Neurath deemed difficult to teach. 'It is hopeless, my dear, to explain Isotype to anybody', he declared to a colleague, 'it is important to get the possibility to show it. ${ }^{57}$ Paul Neurath wrote to his father of the difficulty he had in justifying this approach to his students:

I use[d] to tell them, and this is a pretty verbatim quotation: As to the production of these types of [picture-statistical] graphs there are several opinions. The one held by the originator and main proponent of the method, and author of the books I have shown you, is that nobody can make satisfactory graphs of this type unless he has gone through several years of careful training in the outfit of the author. The method can not be learned from books, not from his own nor anybody else's. He says so on the basis of about twenty years' experience. Now I have my doubt in this opinion. [sic] And particularly do have doubt in general in the usefulness of any method, graphical or technical or sociological or anything, that can not be taught in other ways than by the originator in person, and that is therefore practically doomed to die with the author. ${ }^{58}$

This last observation proved to be rather prophetic. Isotype was inextricable from the economic, sociological and scientific preoccupations of Otto \& Marie Neurath. When Otto Neurath died, Marie Neurath (as co-director of studies at the Isotype Institute) was able to carry on the work. Indeed, the role of the transformer had developed from Marie Neurath's work in the Vienna Method, and, after it was renamed Isotype, she remained the only one filling this role. She seems to have found nobody to train as her successor, and consequently Isotype work stopped when she retired. Nobody has since taken it up in the same way.

If the Neuraths had been more open to free adaptation of their method, it would perhaps have spread more widely, but also more thinly, in a diluted form. It may be possible to trace the influence of Isotype in the incorporation of pictograms into international signage - although this is not the primary influence that Neurath would have wished for. When asked if he would grant permission for Isotype pictograms to be used by others, Neurath replied: 
we feel very strongly that the effect of our method depends not only on the characters, but very largely on the way how they are used [sic], on the selection of representations, on the simplifications, and many other measures. [...] Therefore we cannot allow the use of the symbols if we have no influence on the entire layouts. ${ }^{59}$

Naturally, there was an aspect of protecting professional territory here, but it is perhaps this principle - that pictograms were not the whole point of Isotype - which prevented Marie Neurath from pursuing copyright procedures for Isotype pictograms when she was advised to do so after Otto Neurath's death.

Otto Neurath's dream of universal usage for Isotype and his simultaneous wish to have close control over it were, to a large extent, mutually preclusive. As with other modernist ideals (such as orthographic reform, for example), the individual proponents had no political power with which to enforce their proposals. There was some official sanction given to the Vienna Method in the USSR, where the Council of People's Commissars issued a decree that 'Dr Neurath's method of graphic representation of statistics is to be applied in all schools, trade unions, public and cooperative organizations' ${ }^{60}$ It is not clear to what extent this was enforced; in any case, Neurath would not have approved of an inflexible order to apply the Vienna Method to all kinds of information.

Neurath was in the same position with Isotype as with Logical Empiricism, or more precisely with the use of physicalist, verbal language: he could not institute them (and indeed did not wish to) but could only lead by example. He may have occasionally overstated his claims in these matters, but Neurath was more aware than most people of the difficulties of instituting reforms on a broad basis. Nevertheless, should Isotype be considered a failure for not achieving the true status of an 'international picture language', as Peter Weibel suggested in his paper at the International Wittgenstein Symposium 2010? ${ }^{61}$ Judging by effective projects such as the 'Fighting Tuberculosis' exhibition, seen all over America in the late 1930s, or the civic education programmes in West Africa of the 1950s [see Eric Kindel's chapter in this volume], Isotype can be considered to have achieved significant practical success.

Should we expect Neurath's pronouncements on the international validity of Isotype to have been realized to a greater extent than his equally optimistic proposals for alternative forms of economy, or for a socialist order? Isotype was an early move away from 'mechanical objectivity' towards 'trained judgment' in scientific visualization, to use the terms suggested by Lorraine 
Daston and Peter Galison in their fascinating book Objectivity. Daston and Galison address the vexed issue of failure:

To contend that mechanical objectivity (or, for that matter, trained judgment) is a fraud and a delusion because it is never realized in purest form is a bit like making the same claim for equality or solidarity. These ethical values can change society without ever being perfectly fulfilled, and the same is true for epistemic virtues in science. ${ }^{62}$

Thanks to Robin Kinross and Elisabeth Nemeth. 


\section{Notes}

1 Thomas E. Uebel, Overcoming logical positivism from within: the emergence of Neurath's naturalism in the Vienna Circle's protocol sentence debate (Amsterdam/Atlanta: Rodopi, 1992), 3.

2 'Ich bin kein ausgeklügelt Buch, Ich bin ein Mensch mit seinem Widerspruch' (from Huttens letzte Tage) in Neurath, Empiricism and sociology, edited by Marie Neurath \& Robert S. Cohen (Dordrecht/Boston: Reidel, 1973), 429.

3 Marie Neurath \& Robin Kinross, The transformer: principles of making Isotype charts (London: Hyphen, 2009), 47.

4 Letter Carnap to Neurath, 12 June 1935 (translation by Marie Neurath; Vienna Circle Archive [VCA], Noord-Hollands Archief, Haarlem, Neurath correspondence $227 / 8)$.

5 Letter Neurath to Carnap, 22 June 1935 (VCA).

6 Letter Neurath to Carnap, 30 April 1936 (VCA).

7 Letter Neurath to Carnap, 13 December 1934 (VCA).

8 Neurath recognized the importance of this book, and it made him conscious of his historical place in the Vienna Circle debates. After reading a draft before publication, he remarked to Carnap: 'I must now make a new place for myself in the world and I have a positive interest in my personal achievement being rather more precisely defined in your book.' Letter of 8 March 1934 (English translation by the author; Vienna Circle Archive microfilm [VCA-m], Institut Wiener Kreis, University of Vienna). This also reflects Neurath's preoccupation with making a living at this time; he even wondered about resuming an academic career. Indeed Carnap and Philip Frank made some effort to secure for him a professorship in Prague, but he was rejected on anti-semitic grounds.

9 Letter Carnap to Neurath, 19 December 1934 (VCA).

10 Bildstatistik nach Wiener Methode in der Schule (1933) in Neurath's Gesammelte bildpädagogische Schriften, edited by Rudolf Haller \& Robin Kinross (Vienna, Hölder-Pichler-Tempsky, 1991), 287.

11 Letter Neurath to Carnap, 28 December 1934 (VGA-m).

12 International picture language, 20 \& 32.

13 'Visual education', in Encyclopedia and utopia: the life and work of Otto Neurath (18821945), edited by Elisabeth Nemeth \& Friedrich Stadler (Dordrecht/Boston/ London: Kluwer, 1996), 330.

14 From hieroglyphics to Isotype: a visual autobiography (London: Hyphen Press, 2010), 104.

15 Letter Neurath to R.W. Moore, 23 May 1944 (Otto \& Marie Neurath Isotype 
Collection; Department of Typography \& Graphic Communication, University of Reading [henceforth IC] 1/10).

16 From hieroglyphics to Isotype, 102.

17 Müller, 'Neurath's theory of pictorial-statistical representation', in Rediscovering the forgotten Vienna Circle, edited by T. E. Uebel (Dordrecht: Kluwer, 1991), 232.

18 'Universal jargon and terminology' (1941) in Neurath, Philosophical papers 1913 1946, edited by Marie Neurath \& Robert S. Cohen (Dordrecht/Boston: Reidel, 1983), 229.

19 Neurath cited from Thomas E. Uebel's translation in Overcoming logical positivism from within, 74.

20 Carnap, 'Autobiography' in The philosophy of Rudolf Carnap, edited by P. A. Schilpp (La Salle, Ill.: Open Court, 1963), 29.

21 'Protocol statements' (1932/3), Philosophical papers, 91.

22 'Pseudorationalism of falsification' (1935), Philosophical papers, 128. Neurath pointed out that Carnap's view of protocol sentences differed from his own on this point.

23 'Protocol statements', 91.

24 A similar suggestion is made by Michelle Henning in 'Living life in pictures: Isotype as modernist cultural practice, New Formations (no. 70, Winter 2011): 41-59. I am grateful to her for letting me read it in draft.

25 Neurath [uncredited], 'Form und Farbe der Mengenbilder des Gesellschafts- und Wirtschaftsmuseums', Das Bild (October 1929), 193.

26 Bildstatistik nach Wiener Methode in der Schule, 283; From hieroglyphics to Isotype, 103-4.

27 From two slightly variant translations of 'Wege der wissenschaftlichen Weltauffassung' (1930): the first paragraph is taken from Empiricism and sociology, 82; and the second from Philosophical papers, 46.

28 Feigl, 'The Wiener Kreis in America', in The Intellectual migration: Europe and America, 1930-1960, edited by Donald Fleming and Bernard Bailyn (Cambridge, Mass: Bellknap/Harvard University Press, 1969), 659.

29 'Foundations of the social sciences', International Encyclopedia of Unified Science, vol. 2, no. 1, 48, n. 19 .

30 Letters: Neurath to Morris, 5 January 1938; Morris to Neurath 30 January 1938; Neurath to Morris \& Carnap, 14 February 1938. (English translation by the author; VCA-m.) For more on the relationship between Neurath and Morris, see George Reisch, 'Disunity in the International Encyclopedia of Unified Science', in Logical empiricism in North America, edited by Gary L. Hardcastle \& Alan W. 
Richardson (Minneapolis: University of Minnesota Press, 2003), 197-215.

31 The omission of Semiotic[s] and the favouring of Significs was repeated in Neurath's essay 'Universal jargon and terminology'.

32 'Unified science as encyclopedic integration', International Encyclopedia of Unified Science, vol. 1, no. 1, 21.

33 Patrick Meredith, 'The Visual Education Centre, Exeter', Nature (no. 3907, 16 September 1944): 355.

34 Letter Neurath to Meredith, 15 May 1944 (IC 1/35). Neurath had made a similar point previously in print, warning of the dangers of the 'hasty postulate' of 'complete definiteness'. ('Ways of the scientific world-conception', Philosophical papers, 45-6.) His scepticism was echoed fifty years later by the coiner of the phrase 'the pictorial turn', W.J. T. Mitchell, in Picture theory: essays on verbal and visual representation (Chicago: University of Chicago Press, 1994): ‘... settled answers of a systematic kind may be impossible. This may well be an introduction to a discipline (the general study of representations) that does not exist and never will.' (7) Mitchell continues: 'I am skeptical about the possibility both of transdisciplinary theory and of avoiding "bias" or achieving neutrality in the metalanguages of representation. Although I have great respect for the achievements of semiotics, and draw upon it frequently, I'm convinced that the best terms for describing representations, artistic or otherwise, are to be found in the immanent vernaculars of representational practices themselves.' (14-15, n. 10)

35 Unsent letter from Neurath to Meredith, 22 January 1944 (IC 1/35). 'Logic' is a surprising addition to Neurath's index verborum prohibitorum, which has been usefully reconstructed by George Reisch in 'Economist, epistemologist ... and censor? Otto Neurath's index verborum prohibitorum', Perspectives on Science (vol.5, no. 3, 1997): 452-80.

36 Letter Neurath to Meredith, 15 May 1944 (IC 1/35). Neurath's erratic use of commas in English has been corrected here.

37 Meredith, 'Visual education in the war for health', Health Education Fournal (vol. 1, no. 3, July 1943): 124-9.

38 Unsent letter from Neurath to Meredith, 22 January 1944. Neurath made a similar point in both 'Visual education' (320) and From hieroglyphics to Isotype (109), implying that his discussion with Meredith helped him to formulate his position.

39 Letter Marie Neurath to Meredith, 29 July 1946 (IC 1/35).

40 Letter Neurath to Bühler, 5 September 1937 (VCA-m). Neurath also discussed funding with the Carnegie Foundation (New York) to publish a book based on tests made with Isotype material. (Letter Neurath to Charles Morris, 6 January 1937; VCA-m.) 
41 Letter Neurath to Meredith, 10 June 1941 (IC 1/35).

42 Letter Neurath to H.E. Kleinschmidt, 8 July 1945 (IC 1/46).

43 Letter Neurath to Meredith, 20 July 1944 (IC 1/35).

44 Letter Neurath to Moore, 27 December 1944 (IC 1/10). Moore had mentioned reservations about Isotype in a lecture at the Royal Society, London.

45 Letter Neurath to F. R. Cowell, 13 March 1944 (IC 1/8).

46 'Bildstatistik nach Wiener Methode' (1931), Gesammelte bildpädagogische Schriften, 185.

47 Marie Neurath, 'Bildpädagogik', Die Erziehung (Jg. 7, H. 5, 1932): 315.

48 From hieroglyphics to Isotype, 102.

49 Letter Otto to Paul Neurath, 27 February 1944 (Nachlaß Otto \& Marie Neurath, Österreichische Nationalbibliothek [henceforth ÖNB]).

50 Letter Neurath to Meredith, 24 October 1941 (IC 1/35). See also 'Visual education', 319.

51 'Bildstatistik nach Wiener Methode' (1931), Gesammelte bildpädagogische Schriften, 184.

52 Letter Otto to Paul Neurath, 15 October 1945 (ÖNB).

53 Letter Neurath to Meredith, 27 January 1941 (IC 1/35).

54 'Sociology in the framework of physicalism' (1931), Philosophical papers, 62.

55 From hieroglyphics to Isotype, 102.

56 Undated letter Neurath to H.E. Kleinschmidt [1945] (IC 1/46).

57 letter Neurath to H. E. Kleinschmidt, 8 July 1945 (IC 1/46). By contrast, Carnap wrote of 'transformation rules', which he equated to 'logical rules of deduction', and he considered them 'completely formulable in syntactical terms'. Logical syntax of language (London: Kegan Paul, Trench, Trubner \& Co., 1937), 2.

58 Letter Paul to Otto Neurath, 21 December 1945 (ÖNB). (This was the day before Otto Neurath died, so he did not receive the letter.) The occasionally emotional content of this letter reveals that there were deeper, personal aspects to the disagreement between father and son, which are beyond the scope of this paper.

59 Letter Neurath to Mr James (Calcium Chloride Association, Detroit), 26 November 1941 (IC 1/4).

60 'Museums of the future', Survey graphic (no.9, 1933): 479; see also 'Bildstatistik nach Wiener Methode in der Sowjetunion' (1932) and 'Die pädagogische Weltbedeutung der Bildstatistik nach Wiener Methode' (1933), Gesammelte bildpädagogische Schriften, $207 \& 241$.

61 Weibel, 'Bildsprache und wissenschaftliche Visualisierung', ALWS Kirchberg, 10 August 2010. Weibel contended further that Neurath did not grasp the 'digital 
revolution' - but the digital revolution occurred long after Neurath's death. Should Johann Gutenberg be similarly criticized, despite the benefits that printing with movable type has brought us for more than half a millennium?

62 Objectivity (New York: Zone books, 2007), 377. Daston \& Galison's description of the expert with trained judgment corresponds precisely to the Isotype transformer: 'The expert (unlike the sage) can be trained and (unlike the machine) is expected to learn - to read, to interpret, to draw salient, significant structures from the morass of uninteresting artifact and background.' (328). There are some intriguing parallels between the historical, visual material examined by Daston \& Galison and Neurath's own selection in From hieroglyphics to Isotype.

Unless otherwise stated in captions, all images are taken from the Otto \& Marie Neurath Isotype Collection; Department of Typography \& Graphic Communication, University of Reading, UK.

This essay stems from research carried out for the project 'Isotype revisited', funded by the Arts \& Humanities Research Council and conducted at the Department of Typography \& Graphic Communication, University of Reading, UK. 
